\title{
Faktor risiko jatuh pada lansia di Panti X Surabaya
}

\section{Risk factors for falls in the elderly at Surabaya X Nursing Home}

\author{
Anastasia Putu Martha Anggarani ${ }^{1, *}$, Raditya Kurniawan Djoar ${ }^{2}$ \\ ${ }^{1,2}$ STIKES Katolik St.Vincentius a Paulo, Jalan.Jambi 12-18 Surabaya, Indonesia \\ 1'anastasiamartha@yahoo.co.id*; ${ }^{2}$ radit_stikvinct@yahoo.com \\ * corresponding author
}

Tanggal Submisi: 29 Agustus 2019, Tanggal Penerimaan: 1 Oktober 2019

\begin{abstract}
Abstrak
Tujuan penelitian ini adalah menganalisis faktor risiko jatuh pada lansia. Rancangan penelitian adalah cross-sectional. Sampel sebanyak 36 lansia di Panti X Surabaya diambil dengan menggunakan teknik simple random sampling. Seluruh responden berusia $\geq 60$ tahun, bisa berkomunikasi, membaca, menulis dan menjawab pertanyaan dalam kuesioner. Hasil uji korelasi didapatkan jenis kelamin dan mobilitas mempunyai hubungan dengan jatuh dengan $p 0,023$ dan 0,018. Mobilitas merupakan faktor risiko yang paling kuat berpengaruh terhadap jatuh dengan nilai $p 0,086$ dan $\mathrm{B} 0,408$.
\end{abstract}

Kata kunci: faktor risiko; risiko jatuh; lansia

\begin{abstract}
The study aimed to analyze the risk factors for falls in the elderly. This study was using a cross-sectional approach in 36 elderly in Surabaya X Nursing Home by using simple random sampling. All respondents aged $\geq 60$ years old and can communicate, read, write and answer questions in the questionnaire. Correlation test results obtained by sex and mobility have a relationship with falling with $\mathrm{p} 0.023$ and 0.018 . Mobility is the most influential risk factor affecting falling with $\mathrm{p} 0.086$ and B 0.408 .
\end{abstract}

Keywords: risk factors; fall risk; elderly

\section{PENDAHULUAN}

Proses penuaan menyebabkan penurunan kemampuan fisik yang mengakibatkan lansia berisiko jatuh (Sunarto, 2014). Kejadian jatuh akan menyebabkan penurunan kemandirian lansia dalam melakukan aktivitas fungsionalnya (Kemenkes, 2013). Jumlah kejadian jatuh pada lansia cukup tinggi, setidaknya 28\%-35\% orang yang berusia 65 tahun mengalami jatuh setiap tahun dan jumlah tersebut meningkat menjadi $32 \%-42 \%$ pada lansia berusia 70 tahun (World Health Organization, 2007).

Lansia yang tinggal di panti lebih sering mengalami jatuh dibandingkan lansia yang tinggal di masyarakat. Lansia yang tinggal di panti dalam waktu yang lama $30 \%$ $50 \%$ mengalami jatuh setiap tahunnya dan $40 \%$ dari mereka mengalami jatuh berulang (WHO, 2007). Kejadian jatuh akan menghambat kualitas hidup lansia melalui pengurangan aktivitas fisik, kepercayaan diri, kekuatan dan keseimbangan (Dewi, 2014). Salah satu upaya yang dapat dilakukan untuk mengurangi kejadian jatuh adalah dengan melakukan analisis faktor yang menyebabkan lansia jatuh sehingga dapat 
menentukan tindakan preventif yang tepat (Stephen Lord, 2001). Akan tetapi saat ini faktor tersebut belum dianalisis.

Terdapat beberapa faktor risiko terjadinya jatuh pada lansia (Jette 2012). Faktor risiko yang diteliti dalam penelitian ini adalah jenis kelamin. Beberapa penelitian mengenai kejadian jatuh, menyatakan bahwa kejadian tersebut akan meningkat seiring bertambahnya usia (Friedman et al, 2002). Pada lansia, perempuan lebih berisiko mengalami jatuh daripada laki-laki (Austin, 2007). Pada wanita yang sudah lanjut usia akan terjadi penurunan hormon estrogen yang dapat menyebabkan penurunan massa tulang dan jaringan lunak serta penurunan berat badan. Selain itu juga terjadi kerapuhan jaringan ikat sehingga berakibat langsung pada postur dan biomekanik tubuh (Murphy, 2002). Pada kondisi tersebut tubuh akan mengkompensasi dengan selalu menjaga keseimbangan supaya tidak jatuh. Ketika postur dan biomekanik tubuh berubah, kemampuan tubuh untuk mempertahankan keseimbangan juga akan berubah sehingga menyebabkan mudah jatuh saat melakukan aktivitas (Grabiec et al, 2013).

Faktor risiko lain yang diteliti adalah kemampuan mobilitas lansia. Penurunan kekuatan dan ketahanan otot setelah usia 30 tahun menyebabkan penurunan fungsi aktivitas fisik (Kemenkes, 2014). Saat kekuatan dan ketahanan otot berkurang, maka kemampuan tubuh untuk menjaga keseimbangan saat berjalan dan tersandung menjadi menurun (Martin N, et al, 2016).

Alat ukur untuk mengidentifikasi kejadian jatuh dan faktor risikonya yaitu kuesioner yang menanyakan mengenai jenis kelamin dan kemampuan mobilisasi serta risiko jatuh lansia. Melalui analisis faktor risiko yang telah disebutkan, akan sangat membantu dalam menentukan intervensi yang sesuai bagi lansia yang dapat menunjang pemeliharaan kemandirian, fungsi, kesehatan dan keamanan bagi mereka sehingga dapat dijadikan sebagai upaya preventif untuk mengurangi angka kejadian jatuh pada lansia (Greenberg, 2011).

\section{METODE PENELITIAN}

Penelitian ini menggunakan jenis penelitian analitik observasional di lapangan dengan rancangan cross-sectional. Variabel dependen dalam penelitian ini adalah jatuh, sedangkan variabel independen adalah jenis kelamin dan mobilitas. Penelitian dilakukan di Panti X Surabaya pada 26-31 Oktober 2017.

Subyek penelitian diambil dari lansia di Panti X yang memenuhi kriteria inklusi dan eksklusi sebanyak 36 orang. Kriteria inklusi penelitian ini adalah bersedia menjadi sampel, berusia $\geq 60$ tahun, bisa berkomunikasi dengan baik, bisa membaca dan menulis. Kriteria eksklusi dalam penelitian ini adalah lansia yang tidak bisa menjawab pertanyaan dalam kuesioner. Penelitian ini menggunakan teknik simple random sampling.

Penelitian ini menggunakan alat ukur berupa kuesioner yang mendata mengenai jenis kelamin dan mobilitas. Moblitas lansia diukur dengan menggunakan Elderly Mobility Scale untuk mengetahui tingkat kemandirian lansia (Remilton, 2008). Sedangkan risiko jatuh pada lansia diukur dengan menggunakan Timed Up and Go Test (TUG). TUG Test merupakan alat ukur yang obyektif, valid dan reliabel untuk mengukur keseimbangan saat berjalan (inter rater sebesar 0,94 dan intra rater sebesar 0,95) (Asnandra, 2009).

Data dianalisis dengan menggunakan uji korelasi spearman untuk faktor mobilitas dan contingency coefficient untuk faktor risiko jenis kelamin. Setelah uji 
korelasi dinyatakan signifikan, dilakukan uji multivariat dengan uji regresi logistik binomial untuk mengetahui prediktor kuat variabel bebas terhadap variabel terikat.

Penelitian ini dilakukan atas ijin komite etik penelitian KEPK Stikes Katolik St.Vincentius Paulo Surabaya.

\section{HASIL DAN PEMBAHASAN}

Penelitian ini menghasilkan data distribusi frekuensi berdasarkan karakteristik usia, jenis kelamin, mobilitas dan risiko dengan responden lansia Panti X Surabaya yang di tampilkan dalam tabel 1.

Tabel 1. Distribusi frekuensi berdasarkan karakteristik responden

\begin{tabular}{|c|c|c|}
\hline Variabel & Sub Grup & Total $n=155 \operatorname{Mean} \pm \operatorname{SD} / \mathrm{n}(\%)$ \\
\hline \multirow[t]{4}{*}{ Usia (tahun) } & & $73,57 \pm 9,27$ \\
\hline & Middle Age & $3(8,3)$ \\
\hline & Elderly & $14(38,9)$ \\
\hline & Old & $19(52,8)$ \\
\hline \multirow[t]{3}{*}{ Jenis Kelamin } & Laki-laki & $16(44,4)$ \\
\hline & Perempuan & $20(55,6)$ \\
\hline & Tidak Ada & $23(63,9)$ \\
\hline \multirow[t]{4}{*}{ Mobilitas } & & $15,27 \pm 3,36$ \\
\hline & Tergantung & $3(8,3)$ \\
\hline & $\begin{array}{l}\text { Perlu Bantuan dalam beberapa } \\
\text { aktivitas }\end{array}$ & $5(13,9)$ \\
\hline & Mandiri & $28(77,8)$ \\
\hline \multirow[t]{3}{*}{ Risiko Jatuh } & & $11,22 \pm 5,28$ \\
\hline & Ada Risiko & $25(69,4)$ \\
\hline & Tidak Ada Risiko & $11(30,6)$ \\
\hline
\end{tabular}

Dari tabel 1 menggambarkan informasi mengenai karakter responden penelitian yang berjumlah 36 orang dengan rata-rata usia responden adalah 73 tahun. Responden perempuan lebih banyak 55,6\% dan sebagian besar lansia mempunyai mobilitas yang baik $77,8 \%$. Sebagian responden yaitu sebanyak $69,4 \%$ responden berisiko jatuh.

Tabel 2. Hasil analisi korelasi

\begin{tabular}{clccc}
\hline \multirow{2}{*}{ No } & \multirow{2}{*}{ Variabel } & \multicolumn{3}{c}{ Jatuh } \\
\cline { 2 - 4 } & & rs & C & p \\
\hline 1 & Jenis Kelamin & & 0,353 & $0,023^{\text {b }}$ \\
2 & Mobilitas & 0,393 & & $0,018^{\text {a }}$ \\
\hline
\end{tabular}

a : Uji statistik Spearman'Rho

b : Uji statistik Contingency Coefficient

Tabel 2 menunjukkan bahwa variabel jenis kelamin dan mobilitas mempunyai hubungan dengan risiko jatuh karena $\mathrm{p}<0,05$ (Ho diterima). Kekuatan hubungan variabel jenis kelamin dan mobilitas bersifat sedang karena nilai $\mathrm{C}$ sebesar 0,25-0,5.

Tabel 3. Hasil analisis regresi logistic binomial

\begin{tabular}{ccccc}
\hline Variabel & B & Sig. & Exp(B) & $\begin{array}{c}\text { Cox\&Snell } R \\
\text { Square }\end{array}$ \\
\hline Jenis Kelamin & $-1,423$ & 0,096 & 0,241 & \\
Mobilitas & 0,408 & 0,086 & 1,504 & \\
Konstanta & $-5,339$ & 0,206 & 0,005 & 0,245 \\
\hline
\end{tabular}


Tabel 3 menggambarkan mobilitas merupakan variabel bebas yang paling kuat menjelaskan variabel terikat. Variabel tersebut dapat menjelaskan variabel terikat sebesar 24,5\% adalah benar. Hal tersebut dapat terjadi karena masih ada faktor risiko jatuh lain yang tidak diteliti pada penelitian ini.

Penelitian ini menunjukkan hasil $55,6 \%$ responden adalah perempuan (table 1 ). Hasil analisis korelasi $p$ 0,023 dan $\mathrm{C} 0,353$ (table 2) yang menunjukkan bahwa jenis kelamin mempunyai hubungan dengan risiko jatuh dengan kekuatan hubungan bersifat sedang. Hal tersebut sesuai dengan teori bahwa untuk usia muda, risiko jatuhnya sama. Tetapi pada lansia, jenis kelamin mempengaruhi risiko jatuh dimana lansia perempuan mempunyai risiko lebih tinggi mengalami jatuh dan patah tulang karena jatuh daripada laki-laki (World Health Organization, 2004).

Pada wanita lanjut usia akan terjadi penurunan hormon estrogen yang dapat menyebabkan penurunan massa tulang dan jaringan lunak serta penurunan berat badan (Lopes, 2009). Selain itu juga terjadi kerapuhan jaringan ikat sehingga berakibat langsung pada postur dan biomekanik tubuh. Pada kondisi tersebut tubuh akan mengkompensasi dengan selalu menjaga keseimbangan supaya tidak jatuh (Pluij, 2006). Ketika postur dan biomekanik tubuh berubah, kemampuan tubuh untuk mempertahankan keseimbangan juga akan berubah sehingga menyebabkan risiko jatuh semakin besar (Grabiec et al., 2013). Uji analisis regresi logistik menunjukkan hasil signifikansi $p$ 0,096 dengan arah negatif dengan nilai B -1,423 (tabel 3). Hal tersebut memiliki arti bahwa jenis kelamin merupakan faktor risiko yang berhubungan dengan risiko jatuh tetapi tidak berkontribusi besar menyebabkan jatuh. Selain jenis kelamin, masih ada banyak faktor yang menyebabkan orang berisiko jatuh yaitu riwayat jatuh, tinggal sendiri, etnis, pengobatan yang sedang dijalani, fungsi muskuloskeletal yang dimiliki, takut jatuh, kurangnya nutrisi, gangguan pada tungkai, penglihatan dan faktor lingkungan (World Health Organization, 2007), dimana faktor-faktor tersebut tidak diteliti pada penelitian ini.

Penelitian ini menunjukkan hasil $22,2 \%$ responden tidak memiliki mobilitas yang baik (tidak mandiri) (tabel 1). Hasil analisis korelasi $p$ 0,018 dan r 0,393 (tabel 2) yang menunjukkan bahwa mobilitas mempunyai hubungan dengan risiko jatuh. Menurut teori, kekuatan dan ketahanan akan menurut sebesar 10\% per 10 tahun setelah usia 30 tahun (Surgeons Panel on Falls, 2001). Bila kekuatan dan daya tahan otot menurun maka terjadi perubahan pola jalan dan penggunaan alat bantu jalan semakin diperlukan. Hal tersebut akan berdampak pada sulitnya melakukan aktivitas sehari-hari (De Villiers, 2015).

Uji analisis regresi logistik menunjukkan hasil signifikansi $p$,086 dengan arah positif dengan nilai B 0,408 (tabel 3). Mobilitas merupakan variabel bebas yang paling kuat menjelaskan variabel terikat. Hasil uji korelasi menunjukkan bahwa kekuatan hubungan mobilitas dengan jatuh bersifat lemah dan variabel mobilitas dapat menjelaskan variabel terikat sebesar $24,5 \%$ adalah benar. Hal tersebut dapat terjadi karena disebabkan masih ada faktor risiko jatuh lain yang tidak diteliti pada penelitian ini.

Intervensi yang tepat pada faktor risiko ini maka diperlukan pemeriksaan yang terdiri dari pemeriksaan pola jalan, keseimbangan dan fungsi sendi pada ekstremitas bawah (Taylor, 2012). Salah satu intervensi yang dapat memperbaiki keseimbangan adalah senam Tai-Chi. Hal tersebut ditunjukkan dalam penelitian yang dilakukan Sattin et al tahun 2005 bahwa terdapat peningkatan keseimbangan saat melakukan aktivitas. Tai-Chi merupakan olahraga yang di dalamnya mengandung gerakan lambat, ritmis, 
banyak melibatkan gerakan trunk, pemindahan berat badan, koordinasi, dan penyempitan tumpuan. Senam ini dilakukan selama 60-90 menit selama dua sesi per minggu (Sattin et.al, 2005).

\section{SIMPULAN}

Faktor risiko usia tidak mempunyai hubungan yang bersifat lemah dengan risiko jatuh, faktor risiko jenis kelamin mempunyai hubungan yang bersifat sedang dengan risiko jatuh, faktor risiko penyakit yang sedang dialami tidak mempunyai hubungan dengan risiko jatuh, faktor risiko mobilitas mempunyai hubungan dengan risiko jatuh dan jenis kelamin dan mobilitas merupakan prediktor kuat terhadap risiko jatuh.

\section{SARAN}

Bagi peneliti selanjutnya akan lebih baik jika meneliti lebih banyak faktor risiko jatuh dan bagi tempat penelitian hendaknya melakukan adaptasi lingkungan yang lebih aman dan mengadakan aktivitas fisik berupa senam untuk menambah mobilisasi bagi lansia secara rutin.

\section{DAFTAR PUSTAKA}

Asnandra, Novan. (2009). Uji Reliabilitas Time up and go Test Pada Lansia Perempuan. Politeknik Kesehatan Surakarta.

Austin, Nicole A. D. (2007). Fear of Falling in Older Women: A Longitudinal Study of Incidence, Persistence, and Predictors. Journal of the American Geriatrics Society , 1598-1603.

De Villiers, L. (2015). An approach to balance problems and falls in elderly persons. South African Medical Journal.

Dewi, S. R. (2014). Buku ajar keperawatan gerontik. Yogyakarta: Deepublish.

Friedman, S. M., Munoz, B., West, S. K., Rubin, G. S., \& Fried, L. P. (2002). Falls and fear of falling: which comes first? a longitudinal prediction model suggests strategies for primary and secondary prevention. American Geriatrics Society, 50:1329-13, (papers://85b7707d-3a9d-4f30-bc5c-df0ee0c38a87/Paper/p8739).

Grabiec, J. D., Snela, S., Rykala, J., Podgorska, J., \& Banas, A. (2013). Changes in the body posture of women occurring with age. BMC Geriatrics, 13, (http://doi.org/10.1186/1471-2318-13-108).

Greenberg, S. A. (2011). Assessment of fear of falling in older adults: the falls efficacy scale-international (FES-I). Hartford Institute for Geriatric Nursing, 45(29), (http://doi.org/10.1159/000320054.Kempen).

Jette, Allan. (2012). Fear of falling in older person. Public Health Nursing, 1-8.

Kemenkes. (2013). Riset kesehatan dasar. Retrieved Juli 20, 2016, (www.depkes.go.id/resources/download/general/Hasil\%20Riskesdas\%202013.pdf ) .

Kemenkes. (2014). Situasi dan Analisis Lanjut Usia. Infodatin , 1-8.

Lopes, C. S. (2009). Prevalence of fear of falling among a population of older adults and its correlation with mobility, dynamic balance, risk and history of falls. Brazilian Journal of Physical Therapy, 223-226.

Murphy, S. (2002). Characteristics associated with fear of falling and activity restriction in community-living older persons. Journal of the American Chemical Society, 516-520.

Nilsson, Martin., Eriksson, Joel., Larsson, Berit., Oden, Ander., Johansson, Helena., 
Lorenzton, Mattias. (2016). Fall_risk assessment predicts fall-related injury, hip fracture, and head injury in older adults. Journal of the American Geriatrics Society, 64(11).

Pluij, S. T. (2006). A risk profile for identifying community-dwelling elderly with a high risk of recurrent falling: results of a 3-year prospective study. International Osteoporosis Foundation and National Osteoporosis Foundation, 417-425.

Remilton, N. (2008). The Validity and Reliability Elderly Mobility Scale. Internet Journal Allied Health Science Pract., 60.

Sattin, R. W., Easley, K. A., Steven, M. S., \& Kutner, M. H. (2005). Reduction in fear of falling through intense tai-chi exercise training in older, transitionally frail adults. American Geriatrics Society, 53(7), 1168-1178. (http://doi.org/10.1111/j.1532-5415.2005.53375.x).

Stephen Lord, C. S. (2001). Falls in older people risk factos and strategies for prevention. England: Cambridge University Press.

Sunarto, B. Y. (2014). Buku ajar boedhi-darmojo geriatri (ilmu kesehatan usia lanjut). Jakarta: Fakultas Kedokteran Universitas Indonesia.

Surgeons Panel on Falls. (2001). Guidelines for the prevention of falls in older persons. Journal of the American Geriatrics Society, 49:664-672.

Taylor, Morag M. K. (2012). Gait impairment and falls in cognitively impaired older adults: an explanatory model of sensorimotor and neuropsychological mediators. Age and Ageing , 665-669.

World Health Organization. (2004). What are the main risk factors for falls amongst older people and what are the most effective interventions to prevent these falls? United Kingdom: Health Evidence Network.

World Health Organization. (2007). WHO global report on falls prevention in older age. Perancis: WHO. 